\title{
Examining nurse empathy for infant procedural pain: Testing a new video measure
}

\author{
Margot Latimer RN PhD ${ }^{1}$, Philip Jackson $\mathrm{PhD}^{2}$, Celeste Johnston DEd RN ${ }^{3}$, Jocelyn Vine RN MHS
}

M Latimer, P Jackson, C Johnston, J Vine. Examining nurse empathy for infant procedural pain: Testing a new video measure. Pain Res Manage 2011;16(4):228-233.

BACKGROUND: Research reporting effective pain care strategies exists, yet it is not translated to care. Little is known about how repeated pain exposure has affected nurses' ability to be empathetic and use their knowledge to provide evidence-based care. Concerns have been raised regarding the validity of self-report empathy instruments; therefore, a novel video program was developed for testing. It was hypothesized that those who viewed infants in painful and nonpainful states would have a measureable empathy (pain rating) response correlating to the level of pain expressed by the infants.

OBJECTIVE: To validate the newly developed Empathy for Infant Pain video program (EIPvp) by determining whether nurse and non-nurse control groups' pain scores of 24 video clips showing infants undergoing real medical procedures were equal.

DESIGN: A descriptive cross-sectional video judgement study. controls) were asked to score the infant procedural pain level displayed in the EIPvp using a visual analogue scale and a composite score of known infant pain cues. Participants also scored their own sensitivity to painful events.

RESULTS: Participants rated the videos contained in the EIPvp similarly in three categories (no, low or high pain); however, there were consistent differences between groups within the categories. Nurses scored facial cues for all categories higher than the control group. Nurses scored their own pain in hypothetical situations and that of the infants consistently higher than the control group.

CONCLUSION: The EIPvp yielded predictable responses from both the nurse and non-nurse control groups when scoring the pain expressed in the video clips. Nurses' detection of pain more often than controls may have been an indication that they have greater knowledge of pain cues, or their empathy levels may have been different as a result of their exposure to, or their perceived relationship with, patients. The EIPvp was validated and has promising potential for training and research purposes.

Key Words: Empathy; Neonatal pain; Nursing; Pain assessment; Procedure pain; Situational pain
METHODS: Fifty female participants (25 nurses and 25 allied health

\author{
L'examen de l'empathie des infirmières à l'égard de \\ la douleur que ressentent les nourrissons lors \\ d'interventions : la mise à l'essai d'une nouvelle \\ mesure par vidéo
}

\begin{abstract}
HISTORIQUE : Il existe des recherches faisant état de stratégies efficaces des soins de la douleur, mais elles ne sont pas transposées aux soins. On ne sait pas grand-chose sur la manière dont une exposition répétée à la douleur influe sur la capacité des infirmières à être empathiques et à utiliser leurs connaissances pour fournir des soins probants. On a soulevé des inquiétudes au sujet de la validité des instruments autodéclarés d'empathie. Par conséquent, les auteurs ont mis au point un programme vidéo novateur en vue de le mettre à l'essai. Ils ont postulé que les personnes qui voyaient des nourrissons dans des états de douleur et d'absence de douleur avaient une réaction d'empathie mesurable (taux de douleur) corrélée au taux de douleur exprimé par les nourrissons. OBJECTIF : Valider le nouveau programme vidéo d'empathie à la douleur des nourrissons ( $p v E D N)$ en déterminant si un groupe d'infirmières et un groupe de sujets témoins non infirmières évaluaient l'indice de douleur de manière équivalente dans 24 vidéoclips de nourrissons subissant de véritables interventions médicales.
\end{abstract}

CONCEPTION : Étude transversale descriptive de jugement vidéo.

MÉTHODOLOGIES : Les auteurs ont demandé à 50 participantes ( 25 infirmières et 25 sujets témoins paramédicaux) de coter le taux de douleur que ressentent les nourrissons pendant une intervention démontrée lors d'un pvEDN au moyen d'une échelle analogique visuelle et un indice composite d'indices de douleurs connus démontrés par les nourrissons. Les participants ont également coté leur propre sensibilité aux événements douloureux.

RÉSULTATS : Les participants ont coté les vidéos contenues dans le pvEDN de manière similaire dans trois catégories (aucune douleur, peu de douleur et douleur élevée). Cependant, on remarquait des différences importantes entre les groupes au sein de ces catégories. Les infirmières ont donné une cote plus élevée que le groupe témoin à l'égard des indices faciaux dans toutes les catégories. Les infirmières ont constamment donné des cotes plus élevées que le groupe témoin à l'égard de leur propre douleur dans des situations hypothétique et à l'égard de la douleur des nourrissons.

CONCLUSION : Le pvEDN a suscité des réponses prévisibles du groupe d'infirmières et des sujets témoins non infirmières pour l'évaluation de la douleur exprimée dans les vidéoclips. La détection plus fréquente de la douleur par les infirmières plutôt que par les sujets témoins peut être indicatrice d'une plus grande connaissance des indices de douleur ou d'un taux d'empathie différent en conséquence de leur exposition à leur relation perçue avec les patients. Le pvEDN a été validé et a un potentiel prometteur pour des besoins de formation et de recherche.

Tnfants and children requiring medical treatment in a hospital undergo many procedures that injure the skin and cause pain. Despite many efforts to improve nurse clinicians' pain assessment and management of hospitalized children, evidence indicates that children continue to suffer unnecessarily. Although there is ample evidence to support the use of safe and effective pain care techniques, there are accumulating reports of their underuse in practice. In addition, selfreport tools have not proven consistently useful as predictors of more effective pain care. Therefore, innovative approaches are required to determine why nurse clinicians, who have the knowledge to adequately manage an infant's procedure-related pain, often do not do so in practice. The aim of the present study was to develop and validate a new video instrument - the Empathy for Pain video program (EIPvp) designed to be used for training and research purposes to examine the role that empathy may play in nurses' assessment and management of infant procedural pain.

\section{Children and infants routinely incur pain from tissue-damaging} procedures

Johnston et al (1) found that $45 \%$ of all neonatal invasive procedures performed were heel lances for which no analgesic was given $95 \%$ of the time. In a repeat of that survey 12 years later (2), nearly two-thirds

${ }^{1}$ School of Nursing, Dalhousie University, Centre for Pediatric Pain Research, IWK Health Centre, Halifax, Nova Scotia; ${ }^{2}$ École de psychologie,

Faculté des Sciences Sociales, Université Laval, CIRRIS and CRULRG Research Centres, Laval; ${ }^{3}$ School of Nursing, McGill University,

Montreal, Quebec; ${ }^{4}$ IWK Health Centre, Halifax, Nova Scotia

Correspondence: Dr Margot Latimer, School of Nursing, Dalhousie University, Centre for Pediatric Pain Research, IWK Health Centre,

5850/5980 University Avenue, Halifax, Nova Scotia B3K 6R8. Telephone 902-470-8888, e-mail margot.latimer@iwk.nshealth.ca 
of the heel lances were performed with no pain management strategies. In a recent study (3), a total of 18,929 painful procedures were recorded from 3822 children's charts in eight pediatric centres; only 844 (28.3\%) children received one or more pain management interventions administered and documented specifically for a procedure. Even when nurses demonstrate that they have the theoretical knowledge to assess and manage pain, discrepancies exist between this knowledge and the degree of adequate pain care provided (4-6).

Infants receiving medical care are particularly vulnerable to the negative effects of pain. Specifically, research has documented that infants who experience pain during the neonatal period display a dampened expression to repeated heel lance (7) and exhibit an altered stress response to subsequent painful and nonpainful stimuli $(8,9)$. Given the prevalence of poorly managed pain experienced by children and its association with negative outcomes for this vulnerable population, there is a pressing need to examine the role that attributes such as clinician empathy play in the delivery of more effective pain care.

\section{Does empathy play a role in the delivery of pain care?}

Goubert et al (10) suggested that feeling empathy means to know the experience of another person, and that this consists of cognitive, affective and behavioural components of the self. When we view others in distress, two responses may occur: we may feel distressed ourselves (dispositional empathy) or we may feel sympathy for the other (situational empathy). These responses may occur simultaneously, but they are distinct feelings that have different behavioural outcomes. When we imagine others' distress, we may feel compelled to help, whereas if we only feel our own distress, we may only be motivated to reduce it in ourselves (11). Self-other awareness and perspective taking (situational empathy) allow us to perceive what others feel as though we were experiencing it ourselves (12), but without losing track of the actual source of this feeling. In the present study, we were interested in examining the situational empathy of nurse health care providers for infants undergoing painful procedures.

The role empathy plays in our appraisal and management of pain in others (which is believed to be related to our interpretation of pain in ourselves) has recently sparked considerable interest from scientists, health care executives and clinical practitioners. Exciting new brain imaging research has shown increased activity within a cerebral pain matrix when subjects feel pain following nociceptive stimulation, and when they observe or imagine pain from the same stimuli in others $(13-17)$. It is proposed that this activity is based on an empathetic response, with empathy as a subcomponent measure for pain appraisal. It is of interest to determine how this perception of pain in oneself and others influences the prosocial empathy process in nurses.

The perception-action model proposes that perception of behaviours in others activates the neural mechanisms supporting the same behaviour in the observer $(12,18)$. Typically, in the socialized community, seeing pain expressions provides a signal (emotion) that motivates the observer to behave prosocially (eg, to comfort or help). However, if clinicians attempt to shield themselves and regulate these emotions, they may fail to activate the neural pathways subserving prosocial empathetic responses that motivate them to act on their awareness of the patient's pain. This is of considerable interest given that some have suggested that nurses should suppress their physical and emotional reactions to seeing others in distress to protect themselves from negative sequelae (19-21).

Empathy, which involves taking another person's perspective and acting appropriately toward them (22), is considered to be an essential component of a caring relationship and seems especially critical to the provision of quality nursing care (23). Discrepancies have been reported, however, in research examining nurses' self-reported empathy levels and their behaviours as a result of viewing pain expressed by patients. In research by Watt-Watson et al (24), nurses self-reported moderate empathy levels; however, empathy did not correlate with the amount of analgesia administered or a decrease in the pain intensity of their patients. However, these researchers did indicate that the nurses' empathy levels were positively related to their knowledge and beliefs pertaining to pain assessment and management. This was an encouraging finding from their work, yet in a recent study examining empathy measured by nonhealth care professionals' responses to facial pain cues (25), individuals who scored moderate empathy levels were no better at identifying facial cues or inferring more accurate pain than participants who scored low on empathy.

In summary, previous studies involving self-report measures have found that participants with moderate empathy levels did not score pain experienced by others higher or more accurately. Also, health care professionals did not administer more analgesic or care for patients with lower pain intensity. Essentially, their own dispositional empathy levels did not mean that they more accurately appraised others' pain (ie, situational empathy). This discrepancy between dispositional and situational empathy may explain why clinicians with moderate empathy levels do not increase the frequency with which they manage the pain of their patients. Furthermore, in a recent meta-analysis, Yu and Kirk (26) suggested that a lack of consistency in findings may be related to unreliable or invalid selfreport empathy measures, which is one reason why new mechanisms are being explored to examine nurse empathy for patient pain.

Nurses' ability to empathize or take the perspective of and be sensitive to the patient's pain may, ironically, be compromised as a result of chronically viewing pain expressions of their patients. Indeed, clinicians who repeatedly see patients in pain may become impervious to pain expressions, which may dampen their empathetic response even though they possess the knowledge to do something about it. In an effort to examine the role that empathy plays in nurses' assessment and management of pain in their patients, the following research study was conducted.

Aim

\section{METHODS}

The primary aim was to test and validate a new video task program (ie, EIPvp) designed by the authors to elicit different levels of situational empathy. It was proposed that two groups (nurses and a control group) who viewed video clips of infants in painful and nonpainful states would have a measurable empathy (pain rating) response correlating to the level of pain expressed by infants in the video clips. The secondary aim was to determine how the participants' own sensitivity to painful situations correlated to their empathy scores for the infant's pain.

\section{Objectives and hypotheses}

The specific objectives and hypotheses of the present research were as follows:

Objective 1: To confirm that the video clips included in the EIPvp represented the three pain states (no, low and high pain) and to have this validated by both a nurse group and a non-nurse control group.

Hypothesis 1: Nurses and a control group will score the videos of infants expressing high pain significantly higher than the videos showing low or no pain.

Objective 2: To compare the response to the EIPvp of nurses who regularly view infants in pain from tissue-damaging procedures with a control group who are not regularly exposed to procedural pain.

Hypothesis 2: Nurses will score the high pain videos as painful but the scores will be significantly lower than the control group.

Objective 3: To compare nurse versus control group scores on reported sensitivity to their own pain estimates for hypothetical low and high pain situations.

Hypothesis 3: Nurses will assign significantly lower sensitivity scores for hypothetical painful situations imagined in themselves compared with controls.

\section{Design}

A descriptive cross-sectional video judgement study design was used.

\section{Sample}

Participants were recruited from a single Canadian pediatric tertiary hospital. A total of 50 female participants were recruited ( 25 nurses and 25 non-nurse allied health professional controls). The participants were 

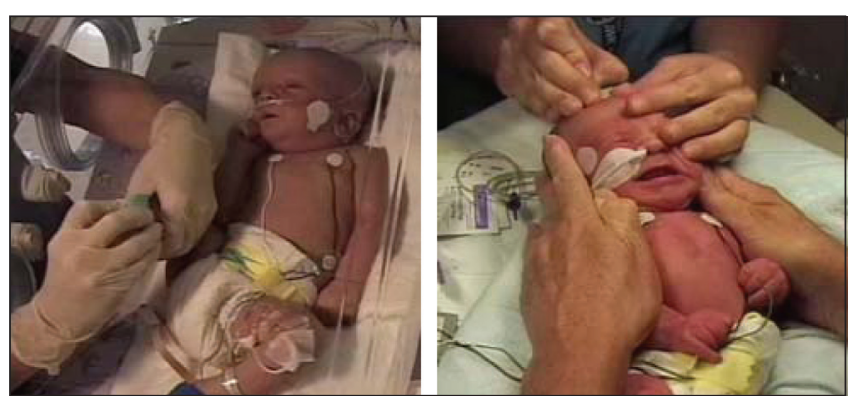

Figure 1) Still frames extracted from video clips showing babies receiving low (left) and high (right) pain procedures

matched for age and university education (ie, baccalaureate or undergraduate degree in their discipline). Registered nurses who provided direct patient care in a surgical, neonatal intensive care, emergency or pediatric intensive care unit were eligible. For the non-nurse allied health professional group, pharmacists $(n=7)$, physiotherapists $(n=4)$, occupational therapists $(n=7)$ and child life specialists $(n=7)$ agreed to participate. Staff were excluded if they worked less than $20 \mathrm{~h}$ per week or had worked for less than 12 months in their disciplinary area, and/or had a history of a neurological, psychiatric or pain-related illness for which they required regular medication. Based on the work of Kozer et al (27), a sample size of 25 in each group was required to detect a difference of two points on the Douleur Aigue Nouveau (DAN) pain scale (28) between the nurse and non-nurse groups, with a power of 0.80 and an $\alpha$ of 0.05 . Twenty-five participants from both groups were randomly selected from lists provided by unit managers using a random numbers table. Of the 50 participants, the majority were between 30 and 49 years of age $(66 \%$ $[n=33])$, with $22 \%(n=11)$ older than 50 years and even fewer between 20 and 29 years $(12 \%[n=6])$. Each participant received a $\$ 20$ movie coupon to thank them for their time.

\section{Data collection}

After obtaining approval from the hospital's research ethics board, the principal investigator shared the study details with unit managers, and a list of eligible participants was obtained. Participants were randomly selected from each of the two groups (nurse and control), and were contacted via an introductory letter delivered to both their electronic and unit mailboxes. Once the purpose and study details were reviewed and consent was obtained, the nurse research coordinator arranged a time to meet with the participants to complete their study involvement. Participants were made aware, verbally and in writing, that their participation was voluntary and they could withdraw at any time. Fifty-two participants were recruited, with two (one from each group) unable to participate as a result of time constraints at work.

\section{Procedure}

Once recruited, participants provided information regarding their age, professional role and length of time in their current position. Next, participants were given a $5 \mathrm{~min}$ description of the scoring rubric involved in the EIPvp (ie, a visual analogue scale [VAS] and the DAN pain assessment scale [28]). Before viewing the EIPvp, participants completed a practice test of two sample clips to ensure they could competently complete the task. The participants viewed the infant pain video program and scored the video clips using both measures (VAS and DAN). Both the VAS and DAN were used for cross-validation purposes. Participants scored the video clips showing infants in three experimental conditions: no pain, low pain and high pain. After the video task testing, participants completed the Situational Pain Questionnaire (SPQ [29]) to determine the participants' sensitivity to hypothetical painful events they might experience.

\section{Measures}

EIPvp: The EIPvp was developed for use in the present study. A nurse with neonatal intensive care and video experience recorded procedures that were performed as part of a neonate's usual and necessary care in the intensive care environment. Consent was obtained from infants' parents to record and use the videos for research and training purposes. The resulting video program includes 24 video clips of different neonates from 35 to 41 weeks' gestation expressing either high pain (eight clips), low pain (eight clips) or no pain (eight clips). The 16 video clips showing low and high pain expression include intravenous initiation (hands, feet and scalp sites) and heel lance procedures (Figure 1), while the eight nonpainful clips include the placement of a patient identification band. The video clips showed real scenarios of infants undergoing necessary procedures, and no attempt was made to alter the nurse or infant's position during taping. The clips show what a nurse would normally view during the procedure including, at times, partially obstructed facial expressions. None of the infants included in the video clips were intubated.

Video clips of pain expressions were selected based on explicit, known pain display indicators (ie, facial expression, limb movement and vocal expression) derived from valid instruments and were precoded initially by two neonatal pain experts. To be selected for inclusion in the painful procedures clips (low or high pain), a pain score of 3 or greater had to be obtained on the DAN (28). Pain expression scores in the 3 to 6 range were defined as low pain, while scores of greater than 6 were defined as high pain. The no pain expressions achieved a score of lower than 3 . The video clips of painful expressions were edited to begin approximately $0.2 \mathrm{~s}$ before the onset of the expression. All of the video clips were edited to last $7 \mathrm{~s}$, which is a duration that has been demonstrated in other research to elicit a valid response $(25,30)$. To ensure that responses were not sequence based, the clips were randomized. Care was taken to ensure that the no pain, low pain and high pain video clips were recorded as similarly as possible in terms of camera angle and lighting. Content validity testing was conducted by asking three expert nurses to review the tapes and provide a score using the known established pain rating scale - the DAN (described below). These scores were compared with the scores provided by the two neonatal experts who assisted with the development of the program, and they agreed more than $85 \%$ of the time. Content validity experts were selected based on their number of years' experience in clinical practice (more than 15 years) and a clinical preceptor designation.

DAN: The DAN is a behavioural scale designed to rate acute pain in preterm and term neonates (30). Pain scores using this tool range from 0 (no pain) to 10 (maximum pain). Treatment interventions are indicated for scores of greater than 3. This tool evaluates three observable pain expressions: facial expression, limb movement and vocal expression. The scale is sensitive for differentiating between painful and nonpainful expressions in preterm and term neonates, and has very good reliability and validity (28).

VAS: The VAS has been shown to have high test-retest and interrater reliability, and high content and concurrent validity for measuring acute pain intensity (31). It consists of a straight, $10 \mathrm{~cm}$ horizontal line with verbal anchors of 'no pain' on the left and the 'worst pain possible' on the right. The $10 \mathrm{~cm}$ line was converted to a $100 \mathrm{~mm}$ line for the global rating scale on the E-Prime computer program (Psychology Software Tools Inc, USA). Higher VAS scores indicated higher assessed pain.

SPQ: The SPQ has been used to determine the typical level of sensitivity to pain and has demonstrated acceptable psychometric properties (29). The SPQ is a self-report tool that assesses the amount of pain an individual believes they would experience in hypothetical situations. It contains 30 items: 15 are considered to be relatively painful (high pain) and 15 are considered to be nonpainful (no or low pain). An example of a high pain situation includes "the dentist drills my teeth without anaesthesia", while a nonpainful situation is "a doctor examines my throat during a check-up". Each item is scored on a numerical scale with 1 being 'indifferent' (no pain) and 10 being 'the worst possible pain'. Higher scores are indicative of higher pain sensitivity to the event. Scores can range from 30 to 300. 


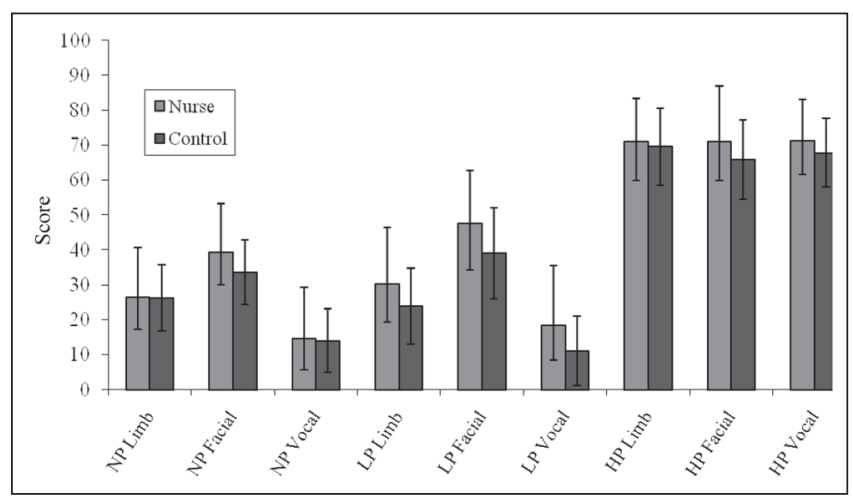

Figure 2) Nurse and control group pain scores for no pain (NP), low pain (LP) and high pain (HP)

\section{Data analysis}

Descriptive, frequency and nonparametric statistics were used to describe and compare the demographic data. An ANOVA was used to examine the differences between empathy self-report (SPQ) and infant pain level empathy (DAN and VAS). A correlation analysis was conducted to determine the strength and magnitude of relationships between outcome measures.

\section{RESULTS}

An initial analysis comparing the amount of pain participants were exposed to in their everyday work showed a significant difference between the nurses and the control group. Using $\chi^{2}$ analysis, nurses $(n=21,84 \%)$ were exposed to pain significantly more often at work (four to five days/week) than the controls $(n=4,16 \%)\left(\chi^{2}[5, n=50]=26.8\right.$; $\mathrm{P}=0.0001)$. In addition, $75 \%(\mathrm{n}=18)$ of the nurse sample reported viewing pain at work the day of testing versus only seven $(24 \%)$ of the control group $\left(\chi^{2}[1, \mathrm{n}=50]=9.68 ; \mathrm{P}=0.004\right)$.

Both groups scored the video clips of infants expressing high pain significantly higher than the low or no pain clips (Figure 2). Overall, the means for the VAS for each of the three levels of infant pain expressed in the video clips (no pain, low pain and high pain) were scored similarly and in the expected range of precoded expert scores. The mean ( \pm SD) score for the VAS of the high pain video clips was $62 \pm 12.9$ (nurse $62 \pm 15$, control $63 \pm 10$ ), of the low pain clips was $32 \pm 14$ (nurse $36 \pm 14$, control $28 \pm 12$ ), and of the no pain clips was $24 \pm 11$ (nurse $21 \pm 12$, control 26 \pm 11 ). Both groups of participants' scores were highly correlated on both the DAN and the VAS $(r=0.79, \mathrm{P}=0.0001)$.

A two-way ANOVA $(2 \times 3)$ was calculated for participants' overall ratings of infant pain expressed in the video clips. A main effect for pain level was found $(\mathrm{F}[2,48]=211.25 ; \mathrm{P}=0.000)$, with higher pain levels receiving higher ratings. The main effect for group was marginally significant $(\mathrm{F}[1,48]=4.02 ; \mathrm{P}=0.051)$, with a small effect size $(\mathrm{r}=0.28)$. When all three levels of pain were collectively considered, the cumulative mean score for all facial cues was higher for nurses $(53 \pm 13)$ than for the control group $(46 \pm 12)$. The interaction term was nonsignificant, but specific level comparisons indicated that nurses scored facial cues significantly differently and higher $(47 \pm 15$ [95\% CI 41 to 53$])$ than the controls $(39 \pm 13$ [95\% CI 33 to 44]) for the low pain video clips $(F[1,48]=4.48 ; P=0.038)$, with a small effect size demonstrated for facial cues $(r=0.29)$. Nurses did not score infants' facial pain expression significantly different from controls in the individual categories of high pain or in the no pain facial category.

The nurse and control groups rated the video clips similarly in all three pain level categories. However, even though the mean scores for both groups were within the expected pain level category, nurses consistently scored pain higher on all three scale scores (limb, facial and vocal) and on the global rating scale (VAS) compared with the control group. Overall, facial actions were the most significant indication of pain expression, showing a small effect size assessed by both groups and highly correlating with overall pain (VAS) $(\mathrm{r}=0.65, \mathrm{P}<0.001)$.

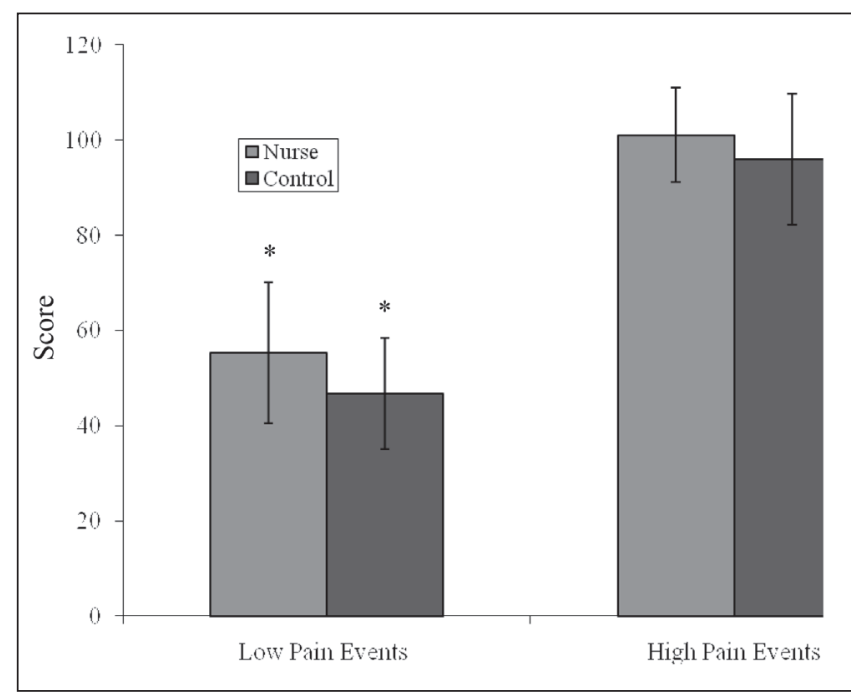

Figure 3) Mean comparison between nurse and control groups on the Situational Pain Questionnaire. ${ }^{*} P<0.01$

To determine whether the two groups were different in their own sensitivity to pain for typical pain events, the participants were asked to complete the SPQ (29). Results from the ANOVA show that nurses scored their sensitivity to low pain events significantly higher (55.0 \pm 14 [95\% CI 49 to 61]) than the control group (46.0 11 [95\% CI 41 to 52$], F[1,48]=5.172 ; \mathrm{P}=0.027$ ), with the variable of nurse showing a moderate effect size $(\mathrm{r}=0.31)$. Nurses also scored the high pain event items higher than controls (101.0 9 [95\% CI 97 to 105] versus $96.0 \pm 13$ [95\% CI 90 to 101]); however, this difference did not reach the significance threshold $(\mathrm{F}[1,48]=2.271 ; \mathrm{P}=0.138)$. There was a small effect size for the group $(\mathrm{r}=0.21)$ (Figure 3 ).

In summary, nurses scored behavioural ratings of sensitivity to painful events in themselves and situational empathy for pain in others (ie, the infants in the video clips) consistently higher than the control group.

\section{Validity and reliability}

In the present sample of nurses and non-nurse health care professionals, the measures demonstrated acceptable reliability. The DAN was used to score each of the EIPvp pain levels, and the high pain category had a Cronbach's alpha of 0.89 , low pain category 0.89 and no pain 0.78 . The VAS was acceptable, with a Cronbach's alpha of 0.74 , while the SPQ had a Cronbach's alpha of 0.90 .

\section{DISCUSSION}

The first hypothesis was supported because both study groups attributed more pain to clips that contained more cues of painful expressions. Both groups validated the EIPvp and scored the painful procedures similarly and in the expected ranges of the three categories of no, low and high pain. While the validation was an anticipated outcome, there were unexpected differences between the groups regarding how participants scored certain infant pain cues (ie, facial expressions) and the range of differences within the pain categories according to group. Subsequently, the second and third hypotheses were not supported. While nurses did score the video clips showing high infant procedural pain as painful, their scores were not significantly lower than those of the control group. In fact, the nurses' scores in almost every instance were higher in all three categories (no pain, low pain and high pain) and significantly higher for the low pain category compared with the control group.

For the present study, we originally wondered whether the reason clinical pain was not being managed more readily was due to an underestimation of the amount of pain the infant experiences or due to an adapted shielding mechanism to the infant's pain expression as a result of chronic exposure at work. We hypothesized that the nurses would have lower sensitivity scores for their own situational pain and would 
also underestimate the pain of the infants in the video clips. This did not occur and, as a result, these findings contribute to an increasing amount of conflicting literature in this area.

Our findings contrast with other reports indicating a tendency in nurses to underestimate the pain of others (32), but they are consistent with other studies that have reported overestimations (33). The current study findings of moderate to high scores of empathy for infant pain (with means of greater than 45/100) are consistent with other studies conducted among nurses $(24,34,35)$ and research reporting that nurses appraise infant procedural pain as higher than other clinicians $(36,37)$. Some researchers have reported a relationship between nurses' self-reports of their empathy level and care outcomes (35,38-41), while other research findings indicate that no relationship exists $(24,34)$. Several self-report measures have been developed and tested, and are reported to be reliable in measuring empathy, including the SPQ (30); however, the authors of a systematic review of nine studies exploring empathy in nurses and nursing students (37) concluded that there was considerable concern regarding the lack of psychometrically sound self-report instruments to measure this concept in nurses. Given these concerns, it may have been helpful to use another instrument, such as the Interpersonal Reactivity Index (42), to measure the groups' self-reported empathy level.

Nurses did not have significantly lower sensitivity scores for typical painful situations imagined in themselves compared with the control group. According to the pain empathy model by Goubert et al (10), empathy depends on bottom-up processes (ie, situational, or what nurses assess or acknowledge as pain cues) and top-down processes (ie, dispositional, or features of the nurses' knowledge and other dispositions). This is consistent with Craig's social communication model (43) and with the findings of knowledge translation researchers (44) in that all identify the unique synergy between attributes of the observer and the context.

According to pain assessment tools developed for nurse use (eg, DAN [28] and Premature Infant Pain Profile [PIPP] [45]), the most powerful bottom-up determinant of the empathic sense of another's pain is the observed facial expression of pain $(17,30,46,47)$. The current study findings support this as an important pain display cue and a small significant effect size resulted for this variable. Although to our knowledge, there has not been specific research examining the relationship between patient facial expression and nurse empathy, in a recent research study (25), a group of undergraduate students were shown video clips of facial expressions of individuals completing a cold pressor pain task (senders), and then asked to estimate that pain experience. This estimate was compared with the senders' actual pain ratings. These researchers reported that higher participant empathy was associated with an overall increase in estimates of senders' pain. However, this was not mediated by the senders' or participants' sex, or the duration of painful facial expressions.

Our finding that nurses who had higher sensitivity scores for painful events in themselves also scored video subjects' pain higher corresponds with an analysis by Green et al (25), which revealed that higher self-report of empathy was associated with greater accuracy in inferring pain in others. Findings from both studies (Green et al and the present study) indicate that while observers with greater empathy may infer greater pain in senders, it is not clear whether they are more accurate in estimating pain for any given stimuli or whether any resulting prosocial behaviour occurs.

The empathy for pain model by Jackson et al $(17,48)$ and the perception-action model (PAM [18]) are helpful, in part, in explaining our findings. Both models propose that one's perception of the viewed object's state automatically activates, in some part, the viewer's representation of the state, priming or generating an associated autonomic and somatic response in the viewer. The resulting perception is based on the relationship between the viewer and the object. PAM proposes that the more inter-related the subject and the object are, the more the observer will attend to the event and the more similar the representations resulting in a response will be. In essence, in addition to having a more activated top-down response as a result of knowledge and context, the nurse sample may have scored the infant's pain consistently higher because they were more knowledgeable and attentive to the pain cues, and felt more of a relationship with the infants as patients compared with the control group.

Animal research has also shown that people and mammals may be more likely to share emotional feelings or empathize with those with whom they have a close relationship (49). Langford et al (50) found that mice exposed to cagemates in pain also displayed pain behaviours themselves, but they did not display the same behaviours as mice that were not their cagemates. Close relationships involve previous interaction, feelings of obligation and a desire to show the other that one cares. However, desire may manifest as an emotion and not always as an actionable behaviour that results in a reduction of the other's pain, only in personal distress for self. In nurses, a desire to manage the pain of others may be present and serve to increase the self-report pain sensitivity scores, but actual prosocial behaviour may be dampened due to contextual or work-related factors.

Empathy in health clinicians is a complex concept to measure. This could be due to poorly developed or unreliable self-report measures for clinicians or work-related variables. Campbell-Yeo et al (51) outlined the challenges in conceptualizing nurse empathy as it relates to clinical practice including nurses' own experiences and exposures in the work context. This sample of nurses was exposed to pain more frequently than the control group and, perhaps, this work-context variable resulted in feeling a sense of overprotection for their patients. In some circumstances, those charged with comforting and helping may become overprotective, impairing their normal or typical responses. Goubert et al (10) suggest that overestimations of pain and distress are likely to occur in contexts with plenty of pain cues (emergency rooms, blood and wounds) and where the top-down influences (ie, knowledge/context) may be substantial. However, it does not appear that overestimations of pain and an overprotective nature translate to increased pain care. In this circumstance, nurse participants were more frequently exposed to pain and rated the neonates' pain higher; however, consistent and reliable research demonstrates that these fragile patients repeatedly endure procedures without the benefit of any pain management $(2,3,5,6)$.

Nurses have knowledge of the best strategies to reduce pain (4-6) and the present study extends that evidence, demonstrating that they not only have the knowledge to accurately assess pain but can do so in a timeefficient manner (ie, $7 \mathrm{~s}$ ). Although the mean scores for both study groups were in the expected range, there were some deviations beyond the expected boundaries, and further refinement and testing of the video program should be conducted. Nurses were exposed to pain and detected pain more often using facial cues compared with the non-nurse control group. These findings support other research demonstrating that clinicians possess greater knowledge and empathy levels regarding infant pain cues $(2,4-6,24)$, yet we continue to be perplexed as to why these attributes do not translate to more effective pain care practice. Higher nurse scores on their own sensitivity for pain estimates and in relation to infants' pain may occur as a result of increased attentiveness and chronic exposure to the pain felt by others. However, we do not know why nurses do not routinely use the effective, evidence-based strategies available to them.

\section{CONCLUSION}

The present study's results met the primary study objective of validating the EIPvp. Although the results advance our understanding of nurses' knowledge of pain assessment and provide early results from a promising new measure for research and training purposes, they also contribute to the inconsistencies in the current body of empathy literature from self-report data, and introduce more questions regarding the role that dispositional empathy may play in situational empathy appraisal of clinicians caring for children in pain. Possession of knowledge and accuracy of pain assessment may not predict prosocial clinician behaviour to reduce children's pain; therefore, the EIPvp is available for use to advance our understanding of how empathy for pain can be examined as a mechanism to increase the translation of clinician's knowledge about pain care to practice. 
ACKNOWLEDGEMENTS: This research was funded by an operating grant awarded by the IWK Interdisciplinary Research Services Department, IWK Health Centre, and was part of ML's postdoctoral research (Jackson, supervisor). The authors thank nurse research assistants Marlene Furlong and Amanda Bettle for their support in conducting the study, and Danielle Schirmer, School of Nursing, Dalhousie University (Halifax, Nova Scotia), for her editorial contributions.

\section{REFERENCES}

1. Johnston CC, Collinge JM, Henderson SJ, Anand KJ.

A cross-sectional survey of pain and pharmacological analgesia in Canadian neonatal intensive care units. Clin J Pain 1997;13:308-12.

2. Johnston C, Barrington K, Taddio A, Carbajal R, EPIPPAIN Canada. Comfort measures for tissue-damaging procedures in Canadian NICU's: Have we improved over the past decade? The Eighth International Symposium on Pediatric Pain. Acapulco, June 7 to 11, 2009.

3. Stevens BJ, Abbott LK, Yamada J, et al; CIHR Team in Children's Pain. Epidemiology and management of painful procedures in children in Canadian hospitals. CMAJ 2011;183:e403-10.

4. Jacob E, Puntillo KA. A survey of nursing practice in the assessment and management of pain in children. Pediatr Nurs 1999;25:278-86.

5. Reyes, S. Nursing assessment of infant pain. J Perinat Neonatal Nurs 2003;17:291-303.

6. Latimer M, Johnston CC, Ritchie JA, Clarke SA, Gilin D. Factors affecting delivery of procedural pain care in hospitalized neonates. J Obstet Gynaecol Neonatal Nurs 2009;38:182-94.

7. Johnston CC, Stevens BJ. Experience in a neonatal intensive care unit affects pain response. Pediatrics 1996;98:925-30.

8. Taddio A, Katz J, Ilesrich AL, Koren E. Effect of neonatal circumcision on pain response during subsequent routine vaccination. Lancet 1997;349:599-603.

9. Grunau RE, Weinberg J, Whitfield M F. Neonatal procedural pain and preterm infant cortisol response to novelty at 8 months. Pediatrics 2004;114:77-84.

10. Goubert LD, Craig KD, Vervoort T, et al. Facing others in pain: The effects of empathy. Pain 2008;118:285-8.

11. Batson CD. The altruism question: Toward a social-psychological answer. Hillsdale: Erlbaum, 1991.

12. Jackson PL, Decety J. Motor cognition: A new paradigm to study self other interactions. Curr Opin Neurobiol 2004;14:259-63.

13. Singer T, Seymour B, O'Doherty J, Kaube H, Dolan R J, Frith CD. Empathy for pain involves the affective but not sensory components of pain. Science 2004;303:1157-62.

14. Singer T, Seymour B, O’Doherty JP, Stephan KE, Dolan RJ, Frith CD. Empathic neural responses are modulated by the perceived fairness of others. Nature 2006;439:466-9.

15. Morrison I, Lloyd D, di Pellegrino G, Robets N. Vicarious responses to pain in anterior cingulate cortex: Is empathy a multisensory issue? Cogn Affect Behav Neurosci 2004;4:270-8.

16. Jackson PL, Meltzoff AN, Decety J. How do we perceive the pain of others? A window into the processes involved in empathy. Neuroimage 2005;24:771-9.

17. Jackson PL, Brunet E, Meltzoff AN, Decety J. Empathy examined through the neural mechanisms involved in imagining how I feel versus how you feel pain. Neuropsychologia 2006;44:752-61.

18. Preston SD, de Waal FBM. Empathy: Its ultimate and proximate bases. Behav Brain Sci 2002;25:1-72.

19. Morse JM, Mitcham C. Compathy: The contagion of physical distress. J Adv Nurs 1997;26:649-57.

20. Morse JM, Mitcham C, van Der Steen WJ. Compathy or physical empathy: Implications for the caregiver relationship. J Med Humanit 1998;19:51-65.

21. Morse JM, Proctor A. Maintaining patient endurance: The comfort work of trauma nurses. Clin Nurs Res 1998;7:250-74.

22. Ickes W. Everyday Mind Reading. New York: Prometheus Books, 2003.

23. Reynolds WJ. The Measurement and Development of Empathy in Nursing. Ashgate: Aldershot, 2000.

24. Watt-Watson J, Garfinkel P, Gallop R, Stevens B, Streiner D. The impact of nurses' empathic responses on patients' pain management in acute care. Nurs Res 2000;49:191-200.
25. Green AD, Tripp MJ, Sullivan T, Davidson M. The relationship between empathy and estimates of observed pain. Pain Med 2009;10:381-92.

26. Yu J, Kirk M. Evaluation of empathy measurement tools in nursing: Systematic review. J Adv Nurs 2009;65:1790-1806.

27. Kozer E, Rosenbloom E, Goldman D, Lavy G, Rosenfeld N. Pain in infants who are younger than 2 months during suprapubic aspiration and transurethral bladder catheterization: A randomized, controlled study. Pediatrics 2006;118:e51-6.

28. Carbajal R, Chauvet X, Couderc S, Olivier-Martin M. Randomised trial of analgesic effects of sucrose, glucose, and pacifiers in term neonates. BMJ 1999;319:1393-7.

29. Clark WC, Yang JC. Applications of sensory detection theory to problems in laboratory and clinical pain. In: Melzack R, ed. Pain Measurement and Assessment. New York: Raven Press, 1983:15-25.

30. Danziger N, Prkachin K, Willer J. Is pain the price of empathy? The perception of others' pain in patients with congenital insensitivity to pain. Brain 2006;129:2494-507.

31. Summers S. Evidence-based practice. Part 2: Reliability and validity of selected acute pain instruments. J Perianesth Nurs 2001;16:35-40.

32. Chambers $\mathrm{C}$, Craig KD. An intrusive impact of anchors in children's faces pain scales. Pain 1998;78:27-37.

33. Redinbaugh EM, Baum A, DeMoss C, Fello M, Arnold R. Factors associated with the accuracy of family caregiver estimates of patient pain. J Pain Symptom Manage 2002;23:31-8.

34. Warner RR. Nurses' empathy and patients' satisfaction with nursing care. J N Y State Nurses Assoc 1992;23:8-11.

35. Wheeler K, Marrett EAM, Lahey EM. A study of empathy as a nursing care outcome measure. Int J Psychiatr Nurs Res 1996;3:281-9.

36. Pillai-Ridell RR, Craig KD. Judgments of infant pain: The impact of caregiver identity and infant age. J Pediatr Psychol 2007;32:501-11.

37. Simons SHP, van Dijk M, Anand KS, Roofthooft D, vanLingren RA, Tibboel D. Do we still hurt newborn babies? A prospective study of procedural pain and analgesia in neonates. Arch Pediatr Adolesc Med 2003;157:1058-64.

38. Murphy PA, Forrester DA, Price DM, Monagham JF. Empathy of intensive care nurses and critical care family needs assessment. Heart and Lung 1992;21:25-30.

39. Reid-Ponte P. Distress in cancer patients and primary nurses' empathy skills. Cancer Nursing 1992;15:283-92.

40. Olson JK. Relationships between nurse-expressed, empathy patient-perceived empathy and patient distress. J Nurs Scholarsh 1995;27:317-22.

41. Olson J, Hanchett E. Nurse-expressed empathy, patient outcomes, and development of a middle-range theory. J Nurs Scholarsh 1997;29:71-6.

42. Davis MH. A multidimensional approach to individual differences in empathy. JSAS Catalog of Selected Documents in Psychology 1980;10:85.

43. Craig K. The social communication model of pain. Can Psychol 2009;50:22-32.

44. Rycroft-Malone J. The PARIHS framework - a framework for guiding the implementation of evidence-based practice. J Nursing Care Qual 2004;19:297-304.

45. Stevens B, Johnston C, Franck L, Petryshen P, Jack A, Foster G. The efficacy of developmentally sensitive interventions and sucrose for relieving procedural pain in very low birth weight neonates. Nurs Res 1999;48:35-43.

46. Williams AC. Facial expression of pain: An evolutionary account. Behav Brain Sci 2002;25:439-55.

47. Botvinick M, Jha AP, Bylsma LM, Fabian SA, Solomon PE, Prkachin KM. Viewing facial expressions of pain engages cortical areas involved in the direct experience of pain. Neuroimage 2005;25:312-9.

48. Jackson P, Rainville, P, Decety J. To what extent do we share the pain of others? Insight from the neural bases of pain empathy. Pain 2006;125:5-9.

49. Cheng Y, Chen C, Lin CP, Chou KH, Decety J. Love hurts: An fMRI study. Neuroimage 2010;51:923-9.

50. Langford DJ, Crager SE, Shehzad Z, et al. Social modulation of pain as evidence for empathy in mice. Science 2006;312:1967-70.

51. Campbell-Yeo M, Latimer M, Johnston C. The empathetic response of nurses who treat pain: A concept analysis. J Adv Nurs 2007;61:711-9. 


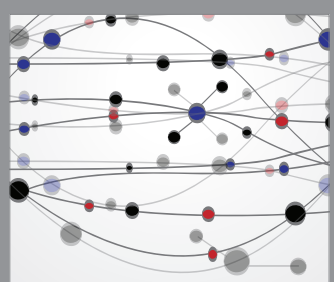

The Scientific World Journal
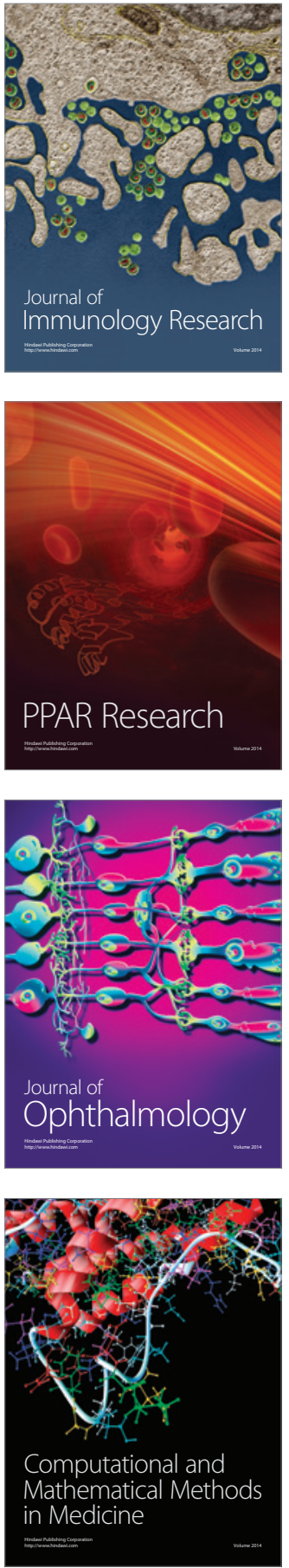

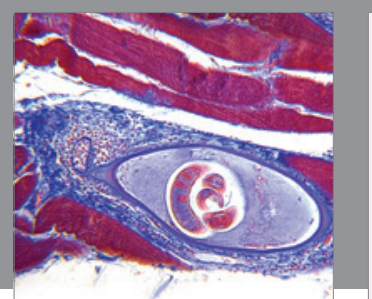

Gastroenterology Research and Practice

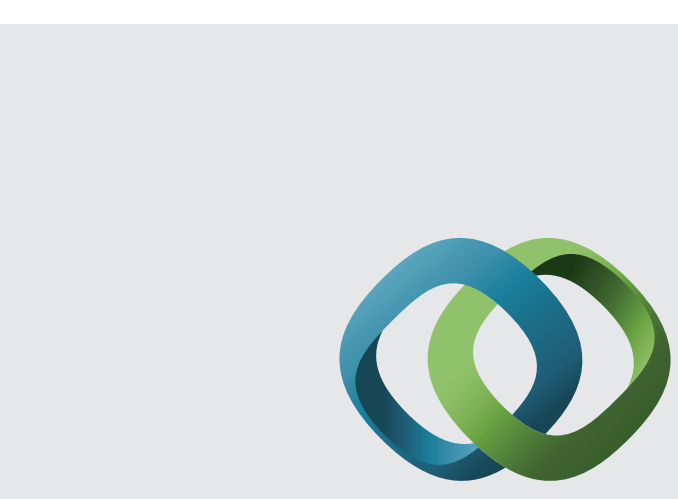

\section{Hindawi}

Submit your manuscripts at

http://www.hindawi.com
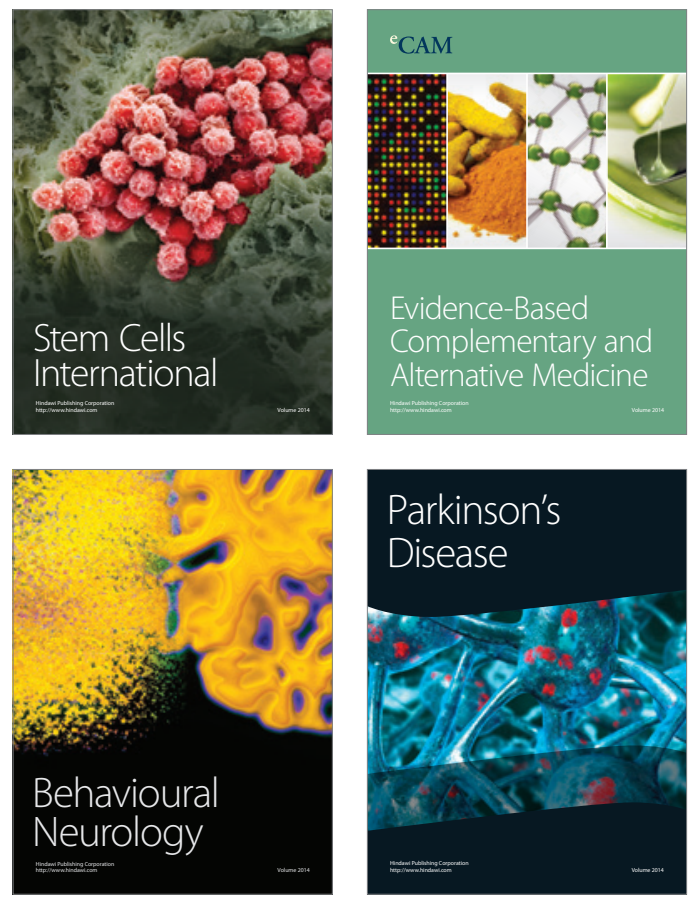
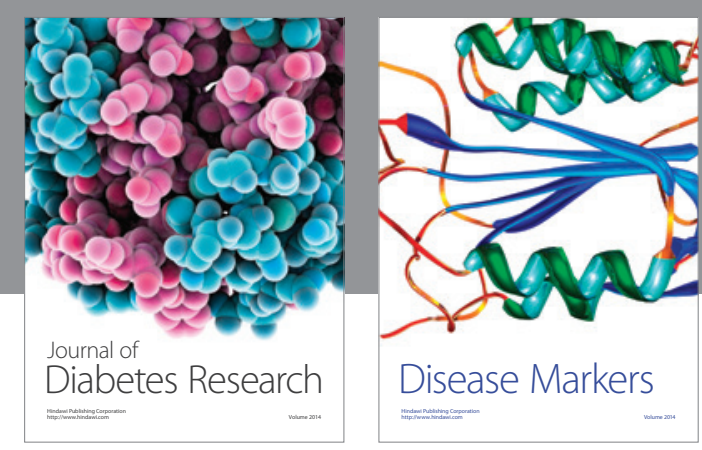

Disease Markers
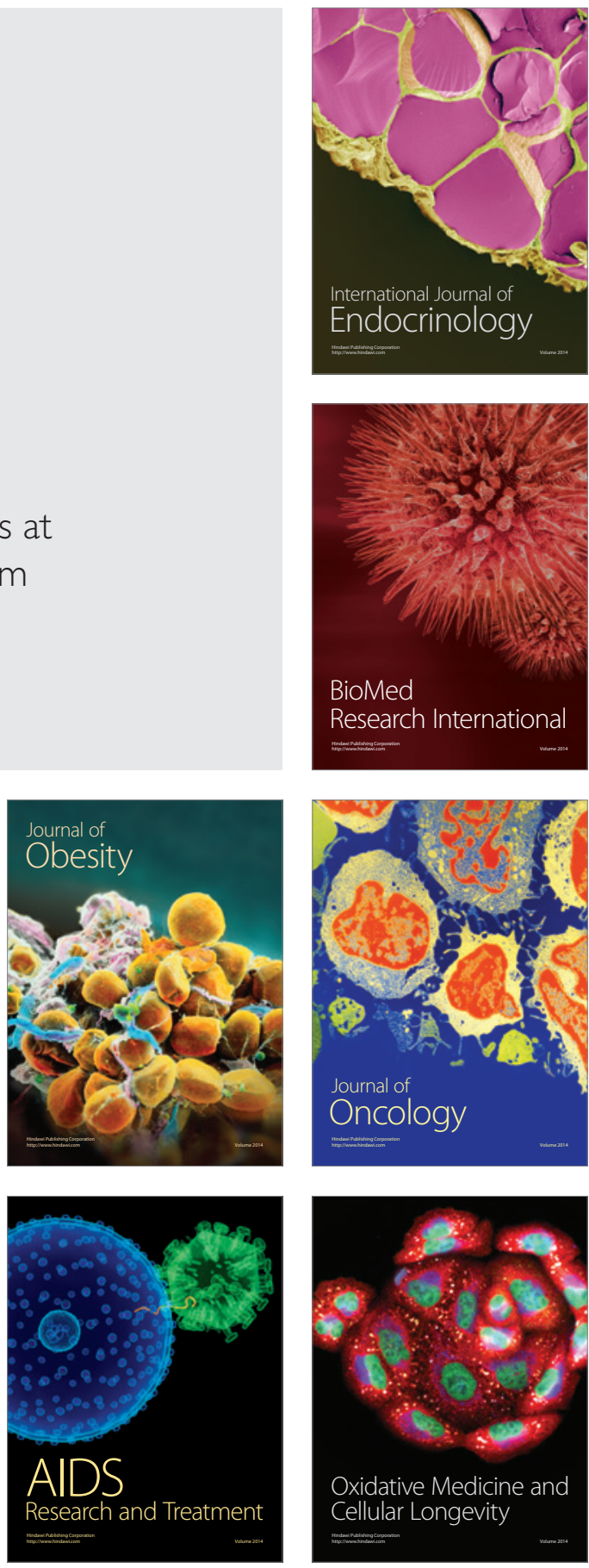